\title{
ESTABLISHING A NATION - KIKILAGA NENEFU
}

\author{
Tony Angelo*
}

There are many challenges in life. Some, such as climbing Mount Everest, circumnavigating the globe, landing on the Moon or exploring Mars, are reported as great human adventures. Few however could be more daunting than being empowered to establish one's identity at a time when knowledge of any previous national identity has, with the passage of a century, largely being lost. That nevertheless is the task set for Tokelau, ${ }^{1}$ a small Pacific nation-6,500 people, of whom only 1,500 live in the cultural homeland and in three discrete villages separated by the high seas.

Tokelau and New Zealand are not approaching this task by following the typical externally driven decolonisation process used by the United Kingdom for its colonies or New Zealand for the Cook Islands or Niue. This paper is concerned with tracing aspects of the semi-autochthonous process so far followed by Tokelau.

** A first glimpse (literally, to see with difficulty or as through a mist). The reference is to the Tokelauan text of I Corinthians 13 'For now we see through a glass darkly'. The Tokelauan phrase was used to describe the preliminary report of the Special Constitution Committee which was established in 1994. The first report of the Committee was received by the General Fono at its meeting of January 1997 (published as Ko na totoga o te Tulafono Fakavae. Tokelau. Elements of the Constitution (Government of Tokelau, 1997)).

* Professor of Law, Victoria University of Wellington.

1 Tokelau refers politically to the 3 Pacific atolls of Atafu, Nukunonu, and Fakaofo (part of New Zealand), and geographically and culturally also to Olohega (now under the administration of American Samoa). Individually the atolls have had a variety of names given by foreign explorers. As a group Atafu, Nukunonu and Fakaofo have been known as the Union Islands and as the Tokelau Islands. The name Tokelau was officially "recaptured" in 1976 - See GA Resolution 31/48 of 1 Dec 1976, and the Tokelau Amendment Act 1976. 
If ever Tokelau ${ }^{2}$ was a clear political identity no living person has first-hand knowledge of it. It is of the nineteenth century, a part of tradition and maintained only in the oral culture. What the communities of Tokelau have in common today is a shared ancestry, a shared culture, a shared language, a shared experience of life in a subsistence oriented environment, and a shared political aspiration.

That aspiration has driven Tokelau to take up the United Nations challenge of decolonisation to reassert a national identity. ${ }^{3}$ The commitment and aspiration to do that was formally announced in the "Voice of Tokelau", a statement by the leadership of Tokelau to the United Nations Visiting Mission on 30 July $1994 .{ }^{4}$

One aspect of this Tokelau decision to embark on its journey of national rediscovery has special legal significance: The constitutional mechanism that is the basis of current Tokelauan national development. This paper will consider the development of the institution of the General Fono in Tokelau and the emergence of the General Fono as the central feature of a rapidly evolving national constitution.

\section{THE BACKGROUND}

Tokelau was made a British protectorate in June 1889 and became part of the Gilbert and Ellice Islands Colony, a later proclaimed protectorate, in 1916. It was excised from the Colony in 1926 and on 1 January 1949 Tokelau was incorporated with, and declared to form part of, New Zealand. ${ }^{5}$

2 Tokelau was possibly, till the 19th century, a feudal kingdom dominated by the chieftainship of Fakaofo. This aspect of Tokelau's pre-colonial history is dealt with in A Hooper "Ghosts of Hierarchy I: The Transformation of Chiefly Authority on Fakaofo, Tokelau" (1994) 7 History and Anthropology 307-320, and J Huntsman "Ghosts of Hierarchy II: Transformations of the Wider Tokelau Policy" (1994) 7 History and Anthropology 321-338.

3 Documents relevant to this issue are collected in Rosemary Gordon (ed) Tokelau. A collection of documents and references relating to constitutional development (Tokelau Administration, Apia, 1995), and the reports of the Administrator of Tokelau presented to the NZ House of Representatives. The reports most pertinent to the topic of this paper are those for the years 1992 and following. The latest report is for the year ended 30 June 1997 (Ministry of Foreign Affairs and Trade, Wellington, 1998).

General information on Tokelau can be found in the Pacific Islands Yearbook, Judith Huntsman and Antony Hooper. Tokelau. A Historical Ethnography (Auckland University Press, Auckland, 1996) Matagi Tokelau, (Institute of Pacific Studies, USP, Suva, 1991), and Tony Angelo "Tokelau - Its Legal System and Recent Legislation" (1987) 6 Otago LR 477, and Tony Angelo "Tokelau Constitutional Developments" 8 Otago LR 413.

4 Reproduced in Report of the United Nations Visiting Mission to Tokelau, 1994 (UN GA, A/AC, 109/2009, 7 September 1994) 26-36; and in Gordon above n 3, 234.

5 Tokelau Act 1948, s 3. 
Till 1949, and for many years after, the administration of Tokelau was conducted on an island by island basis. This reflected both the political and communication realities of the time - Tokelau government in Tokelau existed only in respect of each island, island government was strong, and the assembling of representatives of the 3 islands for national gatherings was impractical.

So things continued till the 1960s when at the initiative of the New Zealand government it was decided to hold a meeting of representatives of the 3 islands for policy planning purposes.

The first combined meeting of the islands, and therefore a forerunner ${ }^{6}$ of the General Fono, seems to have taken place in 1963. The purpose of the 1963 gathering and of the next in December 1964 was to discuss the future relationship between Tokelau and New Zealand. ${ }^{7}$

Further meetings occurred as occasion required. There were for instance two in 1966: one with the Minister, and one with the Administrator. ${ }^{8}$ The New Zealand Departmental reports to Parliament indicate that meetings of all islands tended to coincide with an important official visit: In July 1972 the Administrator "held a General Fono (meeting) with elders from the three atolls"; 9 "The Minister visited the territory in November 1973 and held a General Fono (meeting) with elders from the three islands". ${ }^{10}$ Through the mid-1970s the same reports emphasise that development is on an island by island basis and that local government is in the hands of each Faipule; government of Tokelau as a

6 The meetings of 1963 and 1964 indicated a structure, but the New Zealand government purpose was ad hoc to meet its immediate political needs. Perhaps the true progenitor of the present system was the meeting of January 1966 with the Minister. As a result of that meeting it was reported that "proposals are being formulated to identify the councils with the work of the Administration by giving them a consultative role in determining priority of expenditure" [1966] AJHR A 3, 34.

7 The policy question and the events surrounding this initiative are described in Matagi Tokelau, above n 3, at pages 137-138, and 174. See also Huntsman and Hooper above n 3, Postscript, 316 and following.

8 The Administrator is the person charged with performing the administrative and executive functions of Tokelau. Under the Tokelau Islands Administration Regulations 1949, the Administrator was the High Commissioner of Western Samoa. Now, under the Tokelau Administration Regulations 1993, the Administrator is appointed by the Minister.

9 [1973] AJHR E 14,34.

10 [1974] AJHR E 14, 36. 
whole is for New Zealand officials. Joint meetings, however described, were regular by the 1970s with one a year and then two a year as the expected pattern. ${ }^{11}$

The membership of the General Fono has changed over the years in size and composition. In 1964, ${ }^{12}$ there were 20 representatives from each island, hence a General Fono of 60 members. In 1981, the size of the General Fono was 45 members; ${ }^{13}$ in 1992 the General Fono established its size at 27 members. ${ }^{14}$ In August 1998 it was further resolved that from 1999 there would be 6 elected members from each island and that representation would be for a 3 year term. ${ }^{15}$

In regards to composition there has been a shift from mainly elders to the inclusion of other men and also women, from a process of appointment to election, and from ad hoc membership to a 3 year term. Who the representatives are is, and has always been, a matter of island choice.

The trend has been to reduce the size of the Fono, increase its representativeness, and to democratise the appointment process. The January 1999 elections for the Third National Government (1999-2001) returned: from Fakaofo and Nukunonu - the Faipule, Pulenuku, the Deputy Faipule, the Deputy Pulenuku, a women's representative, and an aumaga representative; from Atafu - the Faipule, the Deputy Faipule, the Pulenuku, a women's representative, an aumaga representative, and a Taupulega representative. There is therefore now a National Government of 15 men and 3 women. ${ }^{16}$

11 Sometimes there are more, sometimes fewer. The General Fono met 3 times in 1998.

12 Described as "a joint fono of the 3 atolls" (Aikman, below n 32) and as "an inter-island conference" Report of the Department of Island Territories for the Year ended 31 March 1965 [1965] AJHR A 5, 7.

13 Tokelau Act 1948 s 2(3), by amendment of 1982, defined the General Fono as "the representatives of the people of Tokelau, usually consisting of 15 persons from each island of Tokelau selected in accordance with traditional custom and usage and usually meeting in session at least once each year".

14 The August 1992 meeting of the General Fono agreed that "members of the General Fono continue to be chosen by the Village Council in the traditional way but be limited to nine from each island, including the Faipule and the Pulenuku".

15 The resolution was that "Each nuku should have a six (6) member delegation to the General Fono. The Fono also encourages the inclusion of women representatives as part of the nuku delegations".

16 This data has been provided courtesy of the Director of the Council of Faipule and the Administrator of Tokelau. Nominations for the women's, the aumaga representatives were made by these groups, but election was by village-wide vote as for the other candidates. 


\section{THE RECORDS}

Tracing the origins, role, legal status and political significance of the General Fono is not easy from the Tokelau side because of the almost complete absence of documentation. One readily accessible statement however is found in Matagi Tokelau at page 174. This is an agreed community statement as at 1991. There it is recorded as follows:

The situation regarding national, Tokelau - wide matters as distinct from local village matters is as follows:

\section{The General Fono}

It is the general fono which decides matters concerning Tokelau as a whole. It is convened at least once every year, usually with each village taking it in turns to host the meeting. Each island's delegation is led by its faipule. There is an equal number of delegates from each island, and they may be chosen from among both the elders and the government employees. Also included in the general fono are the directors of the various sections of the Tokelau office in Apia, together with the Official Secretary, and the Administrator of Tokelau also comes quite frequently from Wellington. The meetings are concerned with issues such as the following:

(a) The work programmes of each branch of the Tokelau Public Service,

(b) Budgetary allocations for the various programmes,

(c) Priorities to be accorded,

(d) Possible sources of funding outside of the regular budgetary allocations.

Other sources of written documentation are the four United Nations Visiting Mission reports of 1976, 1981, 1986 and 1994, other United Nations records, the New Zealand official records, and legislation.

The first United Nations Visiting Mission went to Tokelau in 1976. In its report ${ }^{17}$ at paragraphs 105 and 106 it recorded

The mission was told that the three village fonos were made up of members of the three village councils, while the general Fono consisted of members of the village fonos ...

The general Fono, however, provided for 20 delegates from each island. A trend was beginning whereby teachers and doctors, as well as heads of families or elders, were being designated to

17 UNGA A/AC 109/L 1135. 
the general Fono. Although it had been suggested that women should sit in the general Fono and the village fonos, the practice had not yet been generally accepted.

The balance of the report is a very clear indication of the role of the General Fono at that time and the extensive range of policy matters to which it had given consideration. By the third Visiting Mission in 1986 it was possible to state. ${ }^{18}$

9. The main governing organ for Tokelau is the General Fono, which, over the past five years, has assumed an increasing range of powers for determining Tokelau's development policies and establishing priorities for the expenditure of Tokelau's income. All major policy questions are referred to the General Fono and none has ever been approved by the Administrator or the Minister for Foreign Affairs without the endorsement of the Fono.

10. The General Fono, which usually meets twice a year, insists on 15 representatives of each atoll chosen by its respective taupulega (Council of Elders). These include representatives of the women's committee and the aumaga (village workforce), as well as the elders themselves. The faipule ... are joint chairmen of the General Fono.

11. The General Fono has established three committees, namely Budget, Health and Agriculture and Fisheries. The Health Committee and the Agriculture and Fisheries Committee draw up recommended programmes of activities for inclusion in the budget. The Budget Committee meets prior to the beginning of each financial year to draw up a draft budget for adoption by the General Fono. The respective committees work closely with the Tokelau Public Service during the year to monitor the implementation of their programmes.

12. Officials of the Office for Tokelau Affairs and representatives of the New Zealand Government attend meetings of the General Fono in an advisory capacity.

The General Assembly at its meeting of 4 December 1987 was able to note "the continuing development of the General Fono as Tokelau's highest political body".

In 1994 the Visiting Mission reported in paragraph 14 that: ${ }^{19}$

The principal institution of government in Tokelau is the General Fono (Council), which establishes policies for the administration of the Territory, takes decisions on the allocation of budgetary resources and makes policy decisions in all areas effecting Tokelauan life. The General Fono comprises nine representatives from each atoll chosen by its respective taupulega (Council of Elders)... No major policy question is approved by the Administrator or the Minister ... without the endorsement of the General Fono.

18 UNGA A/AC 109/890.

19 UNGA A/AC 109/2009. 
The General Fono had by that time come of age; its executive authority had by then been formally confirmed.

In the Report of the Administrator of Tokelau for the year ended 31 March 1983 it was stated at page 6

All major policy questions are referred to the general fono, and no such policies have been approved by the Administrator or the Minister of Foreign Affairs, unless the fono's endorsement has been given.

Between meetings of the general fono on all important matters of administration the Official Secretary and directors consult with each island council.

In the Report of the Administrator of Tokelau for the year ended 31 March 1985, page 7:

All major policy questions are referred to the General Fono and no such policies have been approved by the Administrator or the Minister of Foreign Affairs unless the Fono's endorsement has been given.

And in the Report of the Administrator of Tokelau for the year ended 30 June 1992, page 8:

The foremost political institution in Tokelau is the General Fono. It brings together at least once a year representatives of the three atolls to decide policy on Tokelau-wide matters and to endorse the annual budget.

Further in the Report of the Administrator of Tokelau for year ended 30 June 1995 "Tokelau's supreme national body is the General Fono which has developed over some 30 years". 20

Speaking at the Pacific Regional Seminar on decolonisation in Papua New Guinea in June 1993 the Ulu of Tokelau (Chief Minister) reported "The General Fono asking New Zealand to formalise the present informal delegation currently exercised by the Administrator to the General Fono and the Council of Faipule".

For the New Zealand Government matters had already moved on. De facto power had shifted from New Zealand government officials to the Tokelau Faipule. The Administrator of Tokelau speaking at the same seminar did not mention the General Fono but did speak of the Council of Faipule - the Tokelau Cabinet. Similarly the New Zealand Representative to the United Nations when speaking to the Special Committee in New York on 15 September 1994 spoke of the Council of Faipule but did not mention the

20 At 5. 1966 to 1996 appears just-the period from the request to be involved with the Administrator in the national government of Tokelau, till the grant of the legislation-making power. 
General Fono other than perhaps in the general statement "We have seen the development of institutions of self-government in the atolls that did not exist before".

On the legislative front the first reference to the General Fono was in the Tokelau Amendment Act 1982 which came into force on 1 January 1983. It was there recorded in the preamble that the Act was a consequence of a General Fono resolution. The Act itself established a right for the General Fono to be informed of the operation of the newly introduced taxing system and also gave the General Fono a role in any amendment of the Schedule to the Act which related to the rates of taxation. The General Fono was given no direct power, but amendments to the Schedule were to follow if the Administrator was satisfied that the General Fono had resolved that the Schedule be amended. In the Parliamentary debates on this matter the General Fono was described by the Minister of Foreign Affairs as: ${ }^{21}$

Tokelau's highest traditional and customary decision making body, and has representatives from all three islands in the territory. The Fono now plays a major role in all decisions concerning the administration of Tokelau. Tokelau has not, however, reached a stage of selfgovernment at which the Fono has legislative authority. When decisions taken by the Fono need legislation to implement them, that legislation must be introduced into this House.

In 1976 the parliamentary debates also refer to the fact that the passage of the Territorial Seas and Fishing Zone Act for Tokelau was in response to a request from the General Fono. However in that legislation the General Fono itself was not mentioned.

In $1986^{22}$ in the debates relating to the reform of the judicial structures for Tokelau the Opposition spokesperson commented that the Opposition was content if the Bill was "based on a request from the General Fono made to the Government".

The Tokelau Amendment Act 1996 granted legislative authority to the General Fono. In addition, paragraph 11 of the preamble to the Act states

Tokelau also welcomes this Act as a fresh breeze to fill the sails of Tokelau's canoe, and in the knowledge that the conferral of legislative power is a step of large constitutional significance which strengthens the General Fono in its role as Tokelau's supreme national body.

The definition of General Fono that had been added to the Tokelau Act by section 2 of the Tokelau Amendment Act 1982 was repealed by section 2 of the Tokelau Amendment Act 1996, on the basis that the definition was inaccurate and that a current definition was unnecessary.

21 (1982) 448 NZPD 4719

22 (1986) 470 NZPD 1269-1271. 
The General Fono has, since the 1996 Amendment Act, regularly exercised its legislative power and, from the first set of rules it promulgated on 4 November 1996, it has regularly referred to and conferred powers on itself.

\section{FORMALISATION BEGINS}

The history shows that the General Fono was, from its inception till 1993, a forum for discussion but that it had little power and no legal status. It considered policy issues and latterly was responsible for the setting of the annual budget.

The time of big change was 1993-1994. This was the time of relocation of the Tokelau Public Service from Samoa to Tokelau and the taking home of the government of Tokelau. This brought with it the return of power long sought by the elders but also new responsibilities for the leadership of Tokelau. The responsibilities were new in the sense that before 1993 decisions of a national character had been taken either in Apia by public service officers or in the Ministry of Foreign Affairs in Wellington. ${ }^{23}$

The budget discussion meeting held in Apia in July 1992 was a seminal meeting as far as the development of the General Fono was concerned. That meeting considered the promulgation of a simple set of standing orders for the operation of the General Fono and for decision-making at times when the General Fono was not in meeting. The First National Government was for the period 1993 to 1995 . It had the task of taking up the national governmental responsibilities which had previously been held outside of Tokelau. The legal recognition of the empowering of the General Fono followed soon after in 1993 with the repromulgated and amended Tokelau Administration Regulations which made it possible for the Administrator of Tokelau to delegate executive powers to a person other than a public servant. ${ }^{24}$

The Administrator of Tokelau exercised the new power of delegation on 27 January 1994 and conferred the Administrator's executive powers ${ }^{25}$ on the General Fono and, at times when the General Fono was not in meeting, on the Council of Faipule as the standing committee of the General Fono. This delegation complemented Order 11 of the Standing Orders of the General Fono which provides -

23 Though, of course, with reference to any view expressed by the General Fono.

The Ministry of Foreign Affairs took over from the Department of Maori and Island Affairs in 1974: Tokelau Islands Amendment Act 1974.

24 The Tokelau Administration Regulations 1993, reg 5; to be contrasted with the Tokelau Administration Regulations 1980, reg 4.

25 "... HEREBY DELEGATE to the GENERAL FONO all the powers exerciseable by me in respect of Tokelau under any enactment ...." 
11 (1) Where the General Fono is not in session, business of the General Fono shall be referred to the Council of Faipule which shall after such consultation as it thinks fit take the decisions necessary for the effective administration of Tokelau.

(2) All such decisions shall be reported to the General Fono at its next meeting.

This system was built on the existing consultative structure. When important issues had arisen between meetings of the General Fono the practice had been for the head of the civil service (the Official Secretary) or for the Administrator to discuss the matters with the Faipule (the leader of each village) before decisions were taken. In 1993 that pattern of consultation was institutionalised in the form of a cabinet-like structure for Tokelau with the three Faipule alone being responsible for the national decisions.

There was no other background to this development and the three Faipule had no experience of such a collegial national role. The General Fono itself had only slightly more experience of a national role but it was a meeting whose membership changed from one meeting to the next and it had in the past had no institutional power or institutional memory.

\section{CONSTITUTIONAL CENTERPIECE}

The standing orders considered by the Fono planning meeting in Apia in July 1992 were adopted by the General Fono as its rules at its meeting of August 1992. At the same meeting the composition of the General Fono was defined in new terms. Principally the size of the body was reduced. Nowhere were the powers or functions of the General Fono spelled out. It was however accepted that the General Fono was not a forum for village issues, nor was it to supersede the villages. ${ }^{26}$

The Second National Government was for the period 1996 to 1998. It built on the experience of the First National Government and it continued the institutions and practices put in place by that government. It also had the National Strategic Plan, the "Voice of Tokelau" and the 1994 United Nations report as a basis for continuing developments.

26 The village is the foundation of the nation. There is no role for a national government other than to support the villages. See below $\mathrm{n} 29$.

Lack of knowledge of what were national issues often meant that the General Fono did in fact debate village issues.This remains a difficulty: the balance between the functions of a reempowered village and the General Fono is still being sought; the essential national role (albeit small) for the General Fono is not yet part of the Tokelau consciousness. See for example, K Kalolo "Tokelau" (Spring 1999) The Contemporary Pacific 228-236. 
The New Zealand Government had made a commitment to Tokelau and to the United Nations that a law-making power would be conferred on the General Fono ${ }^{27}$ at the earliest possible time. In the event the necessary legislation was passed in $1996^{28}$ and was effective from 1 August 1996. This legislation did not define the General Fono but did give it a significant role. The General Fono was designated as the primary domestic legislator for Tokelau, subordinate to the power of the New Zealand Parliament and of the Governor-General in Executive Council but superior in national legislative terms to the individual villages of Tokelau.

In 1998 Tokelau committed itself to rebuilding the house of Tokelau - rebuilding the national home - and to bringing "all the people of Tokelau under the one rock". ${ }^{29}$ The Special Committee on the Constitution had submitted its first report to the General Fono in January 1997. By resolution in August 1998 the General Fono adopted a number of specific proposals which related primarily to the composition and operation of the General Fono itself. The motivation for these decisions came from the experience from the previous six years: The costs of running the General Fono, the need for continuity of membership of the General Fono, the need to build a body of national political experience, and the need to provide a base for further steps in constitutional development ${ }^{30}$ all informed the decision. The result desired is that the General Fono will from 1999 be smaller, more stable, more efficient and more representative of the various sections of the community.

The General Fono is a creature of custom though not of historical tradition. Its existence and importance is recognised by the legislation of New Zealand and now also by legislation of Tokelau. Its status is no longer conventional but legal. Convention continues to develop in respect of its national role. It is now for instance, almost unthinkable that the New Zealand Government would use its legal rights to override a General Fono decision on a Tokelau domestic matter. ${ }^{31}$

27 Requests for a local legislature had been made by the General Fono from at least the late 1980s.

28 Tokelau Amendment Act 1996

29 The substantive decisions about "The Modern House of Tokelau" were taken by the General Fono of 1-4 August 1998. The allusion is to fish taking shelter in a safe place.

30 For example the role of the head of state, the role of elders, the legislative procedure, and the devolution of the powers of State Services Commissioner (at 1 May 1999 the necessary law changes are before the NZ Parliament in a Statutes Amendment Bill).

31 See Letter of Understanding of 27 January 1994 as to what was delegated and the nature of the reserve powers of the Administrator. 
The General Fono is not defined in New Zealand law. Therefore, if an issue arose as to the nature of the body, that would be decided in the New Zealand High Court either as a High Court for Tokelau using Tokelau law (the Standing Orders of the General Fono are not in Tokelau distinguished from other rules made by the General Fono), or as the High Court for New Zealand with Tokelau law being a matter of foreign law to be proved by fact evidence. This proof is becoming much easier because of the documentation of the activities of the General Fono. The General Fono is fast becoming the National Fono, ${ }^{32}$ and what were the in-house rules of a national meeting of village representatives are now the core of the Tokelau constitution.

Whether the General Fono has legal personality is nowhere stated. The Tokelau description is of a meeting and the perception is probably of a group in meeting rather than of an entity or thing. This view is encouraged and supported by the fact that neither the General Fono nor its executive committee (the Council of Faipule) can be identified with a building or an individual as a representative. ${ }^{33}$ The lack of physical symbols of identity flows from the fact that the meetings of the General Fono and the role of Chief Minister (Ulu) all rotate between villages and individuals, and the decisions of the General Fono and of the Council of Faipule are collegial and consensual. ${ }^{34}$

32 The General Fono is, in 1999, mostly called that in English, and Fono Fakamua in Tokelauan. "Fakamua" means "communal". The translation "general" may have come from Samoan. In the 1960s the translators were Samoans who translated Tokelauan into English and then English into Samoan (for the Tokelau listeners). The Samoan words for what became the General Fono were "Fono tele" and "tele" in Samoan could mean "general" in the sense of "large" or "covering many topics" (Private communication with Tioni Vulu, Tokelau Administration, 6 May 1999). When the name became established is not clear. Professor Huntsman advised (private communication 23 March 1999) - "The December 1964 meeting grandly entitled the First Fono on the Future of Tokelau was preceded in 1963 by the joint fono of the three atolls when they chose to remain with NZ, according, to Aikman in A Ross [ed, New Zealand's Record in the Pacific Islands in the Twenth Century (NZIIA, Wellington, 1969)] 317". In the 1980s references are still found to the "general Fono".

It is interesting to note in the "Voice of Tokelau" (above n 4) that the reference is to the National Fono. That seems to be the usage of political rhetoric and is consistent with the current pattern of development of internal self-government. The UN did not take up the usage in its 1994 report (above n 4).

In practice much may depend on the translator particularly while the constitutional entity in the Tokelau Act 1948 remains described as the General Fono. Fono Fakamua (General Fono),and Fono Fakaatunuku (National Fono) are both heard as also from the time to time are less specific descriptions.

34 Increasingly voting is used to decide non-contentious issues. 
From an external point of view there is equally no clear Tokelau personality separate from that of the Realm of New Zealand. However, the development of such a personality is visible in the status and practice of the General Fono and the Council of Faipule as decision-makers for the three atolls of Tokelau, and in the exercise of an international capacity in an increasing number of matters that impinge on Tokelau internal government. ${ }^{35}$

\section{THE FUTURE}

The destruction of any national governmental identity occurred in the $19^{\text {th }}$ century. The General Fono was a later construct developed to assist modern colonialism. The institution of Faipule was too an imported concept. ${ }^{36}$ Tokelau now is making the General Fono its own. The house is being rebuilt: A modern house for the new millennium.

Tokelau is building from the base up. Foundation stones and supporting pillars have been put in place in the light of experience to date. The third National Government (1999 to 2001) will preside over the furbishing of the house. It may proceed to legislate for more issues central to the operation of national government (for example, land, public service, emergency rules, human rights, courts) by developing or replacing existing rules, it may elaborate the guiding principles of the nation, it may define its own role, and it may do these things by gradual extension of the Standing Orders of the General Fono or it may seek now to separate the key constitutional rules in the Standing Orders from the meeting procedural rules and, as in other jurisdictions, restrict the Standing Orders to the latter. Tokelau will find its own way on these matters in the future as it has since 1992. The direction of movement is clear, the process is clear; the sequence of steps and the Tokelau specific solutions are however likely to be clear only after the event. The New Zealand Government has committed itself to a pattern of Tokelau self-determination for Tokelau and has since 1993 strongly supported Tokelau in the restoring of its national identity. ${ }^{37}$

Comparisons and parallels can be drawn between Tokelau and many other peoples in the exercise of rights of self-determination. The key factor is however the uniqueness of

35 For example, the Memorandum of Understanding with Tuvalu (compare the Treaty of Tokehega, commented on in 17 VUWLR 125), the Tokelau membership of SPREP, and its relationship to the WHO.

36 Faipule appears as a Samoan borrowing at least a century ago. The new usages of $u l u$ and aliki, for Chief Minister and Minister respectively, appear to be a drawing on Tokelau tradition.

37 For example, the Tokelau Administration Regulations 1993, the delegations, statements to the United Nations, the 1996 Act, the telephone system, the acquisition of the ship Forum Tokelau, and the appointment of a Tokelauan as Tokelau Public Service Commissioner from September 1998. 
the challenge for each nation. Focus on comparative examples risks obscuring this essential fact and in denying to the people concerned a true determination. Tokelau alone knows what it is and what it wishes to be. It is only commitment to its future by the self-determining nation that will make it something more than a pale image of some other.

The New Zealand Government has typically been benign and supportive of Tokelau but only recently has it committed itself to Tokelau's establishing the goals for Tokelau. The presumption in Wellington till recently was probably that Tokelau would follow the pattern set by the New Zealand Government in the Cook Islands and Niue.

A number of factors undoubtedly conspired to produce the present policy on Tokelau. Notable among them (and not necessarily in order of priority) were the widening range of thought among Tokelauans (flowing from education overseas, more travel beyond Tokelau and government as a topic of general discussion), the appointment of a fulltime Administrator in 1992, the absence of a New Zealand Government presence in Tokelau, increasing United Nations pressure to complete the decolonisation process by the turn of the century, a worsening New Zealand economic situation, a lack of interest on the part of Tokelau (and even some resistance) to following the path of the Cook Islands and Niue, the increasing social economic and environmental impact on Tokelau of the outside world, and the strong desire of the elders of Tokelau to have authority over Tokelau restored to Tokelau.

What is unfolding is therefore unique to Tokelau - to have a relatively decolonised pattern of self-determination - but also unique for New Zealand in its decolonising experience.

The situation is not that of a Samoa eagerly anticipating the end of colonialism, nor is it the Westminster-style approach to the grant of self-government that was used in the Cook Islands and Niue. After a long period of constitutional quiescence, Tokelau has since 1992 surprised with its development of internal self-government and with its selfestablished approach to that development.

There is much that is familiar in this decolonisation pattern of Tokelau:

- development of internal self-government through the offices of a local central agency;

- $\quad$ conferral of an executive authority before legislative authority ;

- $\quad$ exercise of executive authority by delegation before the transfer of executive authority;

- composition of the local central agency moving from appointees to elected representatives.

What is perhaps unfamiliar is that: 
- the definition, composition and role of the local central agency has been left to the people of the territory;

- control of the central local agency has always been local and the composition, whether by appointment or through the electoral system, was the choice of the people of the territory.

This suggests, in general terms, that the development of internal self-government in Tokelau is following a pattern of recognition of authority by the colonial government rather than of a transfer of authority by the colonial government. All of which predicates the existence of a colonial political environment in which such a pattern is possible. This is a pattern of autochthony.

Another three years of such development raises the possibility of an act of selfdetermination earlier rather than later, and the need for readiness by the Government of New Zealand to complement the Tokelau decision-making process. The constitutional development of Tokelau is not the only factor and probably not the key factor in the move towards an act of self-determination. Nevertheless constitutional development in Tokelau has to date been a reliable indicator as to the developing decolonisation status of Tokelau.

It is not unusual in national constitutional development of an evolutionary or revolutionary kind to see an informal self-created institution such as the General Fono take on a key formal role. It is unusual for this to happen in a formal decolonisation process such as that of Tokelau. 
